\title{
Os desafios da regionalização do SUS no contexto federativo brasileiro
}

\author{
The challenges of SUS's regionalization in the Brazilian federative context \\ Los desafíos de la regionalización del SUS en el contexto federativo brasileño \\ Julio Cesar Donisete Santos Souza ${ }^{1}$ \\ Alethele de Oliveira Santos ${ }^{2}$
}

RESUMO. Objetivo: Este artigo discute o desenvolvimento da regionalização do SUS e sustenta que o processo obedeceu a três etapas: a descentralização rumo a uma estruturação das redes municipais de saúde; a estruturação das regiões com redes hierarquizadas de serviços de saúde e aos desenhos institucionais de participação negociada (Pacto da Saúde); e, da regionalização contratualizada, na qual o Contrato Organizativo de Ação Pública (COAP) se constitui como instrumento de referência. Metodologia: O enfoque metodológico empreendido na elaboração deste artigo foi o do tipo qualitativo, decorrendo daí uma análise bibliográfica de literatura especializada capturada a partir dos descritores Federalismo brasileiro e Regionalização da Saúde. Resultados: O federalismo brasileiro apresenta disfunções e falta de capacidade coordenativa. Conclusão: Pode-se inferir que o processo de regionalização do SUS sofre com os descaminhos do pacto federativo nacional, além das tensões atinentes à própria disputa em torno do fundo público da saúde.

Palavras-chave: Federalismo. Política de Saúde. Regionalização.

ABSTRACT. Objective: This article discusses the development of SUS's regionalization and maintains that the process followed three stages: decentralization towards a structuring of municipal health networks; the structuring of the regions with hierarchical networks of health services and the institutional designs of negotiated participation (Health Pact); and of contractualized regionalization, in which the Public Action Organizational Contract (PAOC) constitutes a reference instrument. Methodology: The methodological approach undertaken in the elaboration of this article was qualitative, resulting in a bibliographical analysis of specialized literature captured from the descriptors Brazilian Federalism and Regionalization of Health. Results: The Brazilian federalism introduce dysfunctions and lack of coordinating capacity. Conclusion: It can be inferred that the SUS's regionalization process suffers from the misconduct of the national federative pact, in addition to the tensions related to the dispute itself about the public fund of health.

Keywords: Federalism. Health Policy. Regional Health Planning.

RESUMEN. Objetivo: Este artículo discute el desarrollo de la regionalización del SUS y sostiene que el proceso obedeció a tres etapas: la descentralización hacia una estructuración de las redes municipales de salud; la estructuración de las regiones con redes jerarquizadas de servicios de salud y los diseños institucionales de participación negociada

\footnotetext{
${ }_{1}^{1}$ Advogado e Mestrando da Faculdade Latino Americana de Ciências Sociais. Ministério da Saúde. E-mail: juliodir@gmail.com

2 Assessora Jurídica do Conselho Nacional de Secretários de Saúde. Advogada e Doutoranda em Saúde Coletiva pela Universidade de Brasília. E-mail: alethele@ig.com.br
} 
(Pacto de Salud); y de la regionalización contractualizada, en la cual el Contrato Organizativo de Acción Pública (COAP) se constituye como instrumento de referencia. Metodologia: El enfoque metodológico emprendido en la elaboración de este artículo fue el del tipo cualitativo, resultando de ahí un análisis bibliográfico de literatura especializada capturada a partir de los descriptores Federalismo brasileño y Regionalización de la Salud. Resultados: El federalismo brasileño apresenta disfunciones y falta de capacidad coordinadora. Conclusión: Se puede inferir que el proceso de regionalización del SUS sufre con los descaminos del pacto federativo nacional, además de las tensiones relativas a la propia disputa en torno al fondo público de la salud.

Palavras-Ilave: Federalismo. Política de Salud. Regionalización.

\section{Introdução}

Construir um sistema público de saúde de acesso universal, gratuito e com atendimento integral é, indubitavelmente, um avanço civilizatório quando se leva em consideração uma sociedade profundamente marcada pela desigualdade social e regional, na qual a força de trabalho se reproduz em condições precárias e que raramente cultiva uma cultura democrática e cidadã. Ainda assim, passadas três décadas desde a promulgação da Constituição Federal de 1988, a qual assimilou os pressupostos do Movimento da Reforma Sanitária Brasileira ao dispor que a saúde é um direito social a ser garantido pelo Estado por meio de políticas econômicas e sociais que culminaram na criação do Sistema Único de Saúde (SUS), são inegáveis os progressos obtidos em diversas dimensões, como a cobertura dos programas de imunização, a política de prevenção e tratamento aos portadores do vírus HIV, os procedimentos de transplantes de órgãos, a estruturação, ainda que incipiente, de uma rede de atenção básica etc., em que pese os entraves impostos por anos de subfinanciamento e por um modelo de atenção ainda centrado no binômio "hospitalmédico".

A forma federativa adotada pela Constituição Federal prezou por um sistema em que os entes conformam uma relação de cooperação, sob a qual, mantendo suas respectivas competências, colaboram entre si na tarefa de promoção de políticas em benefício à população. Tal engenharia institucional, necessariamente, requer uma sofisticada governança política para coordenar a relação federativa, mediando as tensões e regulando os limites ao exercício do poder dos atores políticos em negociação. Nesse sentido, a implementação de políticas em contextos federativos complexos, como é o caso brasileiro, 
não é apenas uma questão de desenho ou de gerência, mas também de articulação política e estratégia de coordenação.

O SUS talvez seja o exemplo mais acabado de uma política que pressupõe uma ampla cooperação e coordenação interfederativa. O próprio art. 198 da Constituição adianta que as ações e serviços de saúde compreendem um universo em que os diferentes níveis de atenção se articulam em base territorial nas regiões de saúde, obedecendo as diretrizes da descentralização, do atendimento integral e da participação da comunidade. A estratégia para dar cabo a essa tarefa, em especial após a edição das Leis no. 8.080/1990 e no. 8.142/1990, foi a da regionalização.

Neste artigo, a regionalização, a descentralização e a municipalização serão tratadas como partes de um mesmo movimento, preservando características políticas e institucionais bastante semelhantes. A regionalização do SUS obedeceu a um amplo clamor da sociedade civil e das esferas subnacionais de governo que reivindicavam um modelo de saúde com maior capilaridade local que, dentre outras vantagens, possibilitaria controle social e adequação das ações e serviços às distintas realidades territoriais. Neste aspecto, procurarse-á demonstrar como a soldagem política e normativa do contexto federativo brasileiro é parteira do processo de regionalização do SUS, inclusive nas dificuldades e desarranjos encontrados durante todo esse tempo de desenvolvimento.

Considera-se que o processo de constituição de um sistema de saúde regionalizado respeita uma agenda política que até o momento desdobrou-se em três etapas. A primeira delas, iniciada logo após a aprovação da Lei Orgânica da Saúde (Lei no․ 8.080/1990 e Lei no. 8.142/1990), consistiu na edição das conhecidas Normas Operacionais Básicas (NOB) e de Assistência à Saúde (NOAS), cujas principais heranças, conforme se verá, foram o estabelecimento de procedimentos a serem observados pelos entes subnacionais a título de recebimento das transferências financeiras federais e o avanço da municipalização das ações e serviços de saúde. A segunda etapa pode ser caracterizada pela elaboração do Pacto pela Saúde, datado de 2006, sob o qual a estratégia da regionalização buscava afastar-se de certa regulação impositiva da esfera federal e trilhar o caminho da gestão compartilhada, com definição das responsabilidades de cada ente federativo, de metas sanitárias e compromissos pactuados entre os gestores alicerçados nos três componentes do programa: o Pacto pela Vida, o Pacto em Defesa do SUS e o Pacto de Gestão do SUS. Por fim, a edição do Decreto nº. 7.508/2011 criou novo instrumento administrativo no âmbito 
da gestão regional em saúde, como é o caso do Contrato Organizativo de Ação Pública na Saúde (COAP), que pode ser entendido como uma tentativa de estabelecer uma nova governança federativa, de natureza contratual, que tem como objetivo materializar 0 compromisso entre os atores federativos ao redor da integração de ações e serviços de saúde de uma determinada região, avançando na estratégia de coordenação federativa pautada na definição clara de responsabilidades de cada ente e de metas a serem atingidas.

O objetivo deste artigo é desenvolver uma observação analítica acerca do processo da regionalização do SUS compreendendo-o sob a perspectiva de um contexto federativo marcado pela baixa capacidade dos governos em conjugar esforços para superar os enormes problemas nacionais, sendo um deles a oferta adequada de ações e serviços de saúde a toda a população. Desta forma, a primeira parte será dedicada a discutir a questão federativa, em especial, o federalismo brasileiro e sua relação com a política de saúde. A segunda parte abordará os meandros do processo de regionalização do SUS tendo como referência as três etapas descritas acima.

\section{Metodologia}

O enfoque metodológico empreendido na elaboração deste artigo foi o do tipo qualitativo. Segundo Sampieri, Callado e Lúcio (1), "o enfoque qualitativo pode ser pensado como um conjunto de práticas interpretativas que tornam o mundo 'visível': o transformam em uma série de representações na forma de observações, anotações, gravações e documentos". Suas características podem ser assim elencadas: explora os fenômenos em profundidade, o que possibilita uma melhor contextualização dos mesmos; os significados do objeto de pesquisa são extraídos dos dados; possibilita o uso de diversas técnicas de pesquisa e habilidades sociais, de acordo com a situação exposta; as hipóteses são construídas durante o processo e vão se aprimorando conforme o desenvolvimento da coleta dos dados, entre outros.

Pela natureza do objeto, a pesquisa consistiu em análise bibliográfica e documental (normativa). O acervo bibliográfico foi constituído por literatura especializada capturada a partir dos descritores "Federalismo" e "Regionalização da Saúde". Seguindo o mapa de literatura (ou autores) de Creswell (2), cada um desses termos correspondeu a uma "caixa", que se desdobrou numa lista de autores preenchida durante todo o processo, a partir de citações cruzadas e da bibliografia. As publicações foram selecionadas em bibliotecas 
físicas, periódicos nacionais (como as revistas de programas de pós-graduação em saúde, política social entre outros), e em bases digitais como Scielo, LILACS, BVS e Google Acadêmico. Foram consultadas, em especial sobre o tema da regionalização, publicações institucionais do Conselho Nacional dos Secretários de Saúde (CONASS) e do Ministério da Saúde.

\section{Breve análise sobre o Federalismo no Brasil: o SUS como política de cooperação e coordenação federativa}

O federalismo talvez tenha sido a principal bandeira que efetivamente uniu os setores sociais que formaram a coalizão que culminou na instalação da República, tendo como inspiração o modelo já em vigência nos Estados Unidos da América (3). Na prática, o início do federalismo brasileiro significou a derrota de um modelo altamente centralizado na União, cujo poder, recursos e instrumentos de intervenção se tornaram extremamente fracos em benefício de maior autonomia para os estados, no qual a questão tributária foi a que melhor exemplificou este conflito ${ }^{3}$.

A literatura, tanto jurídica quanto relativa à ciência política, compreende a Federação como uma ideia de "união", de "pacto", ou seja, uma articulação entre suas partes (estados), coordenada por um ente central, o Governo Federal ${ }^{4}$. Para Fiori (5) é reconhecidamente difícil formular uma definição conceitual sobre federalismo, haja vista a própria imprecisão na ciência política sobre qual seria uma divisão adequada do poder e as formas institucionais mais corretamente elementares de um país federalista. Ainda assim, sublinham-se algumas pistas centrais para sua categorização, como os aspectos de "barganha pragmática" (ou negociação federativa) que moldam o pacto federativo, cuja roupagem pode ter "infinitas formas legais e institucionais, dependendo das condições de sua negociação em cada

\footnotetext{
${ }^{3}$ O modelo de repartição tributária constituído na primeira República da Constituição de 1891 privilegiou poucos Estados (SP e MG, em especial), o que, nas palavras de Salvador (4), indica que a Federação brasileira foi constituída pela concentração de recursos e por escassas relações entre seus entes constitutivos. Por óbvio, uma das consequências dessa opção política foi o fortalecimento das regiões mais desenvolvidas e o aumento das desigualdades sociais e regionais que até hoje perduram no país.

${ }^{4}$ Ainda que se considere que a definição taxativa acerca de categorias que envolvem processos políticos e sociais seja deveras empobrecedora, pode-se dizer que por Federação entende-se uma forma territorial de organização do poder, no qual se articulam o poder central e os poderes regionais e locais. A interação entre esse complexo de poderes pode se dar através de um "pacto federativo", que consiste num amplo e profícuo entendimento entre os atores federativos para a consecução de políticas públicas, envolvendo, por conseguinte, a distribuição do fundo público.
} 
momento e em cada lugar", porquanto as questões jurídico-constitucionais ou políticoconstitucionais assumem posição secundária ou meramente derivada do processo de negociação entre os atores em uma dada correlação de forças. Para o autor, federalismo é uma forma de organização territorial do poder dos Estados-nação permeada necessariamente por uma "permanente tensão e desarmonia entre as partes", resultando em um perene processo de negociação do qual decorrerão arranjos institucionais transitórios.

Affonso (6), ao discorrer sobre a crise do pacto federativo após a Constituição, afirma que, no caso brasileiro, federalismo é relacionado ao processo de descentralização de competências. Ao contrário do que ocorrera na questão estadunidense, a federalização por aqui não foi um processo pelo qual as colônias se juntaram para formar um Estado Federal, conquanto que o Governo Central se constituiu como "parteiro" das esferas subnacionais, num processo top down (de cima para baixo), já que se tratou de um acordo entre as classes dirigentes para manter uma precária unidade do território nacional.

Importante trazer à baila que a organização federativa de Estado se baseia em dois princípios básicos: a autonomia e a participação (7). Ao primeiro, a melhor síntese é a autodeterminação garantida institucionalmente. Sua consequência prática reside na descentralização enquanto forma de fortalecimento dos entes subnacionais. Por participação, destaca-se a responsabilidade que cada ente possui para a governança do sistema, ensejando aí a noção de cooperação das ações de cada ente para a realização de objetivos comuns. É corriqueira no debate sobre federalismo, talvez um "quase consenso", a ideia de que a esfera local, no que tange aos processos de tomada de decisão e execução de políticas, possua maiores vantagens em relação às instâncias governamentais centrais pelo fato por estar mais bem situada em termos de proximidade no que tange aos usuários dos serviços e bens públicos.

Para Amaral Filho (7), o princípio da cooperação é essencial para a governança e sustentabilidade da federação. No entanto, é pouco levado em consideração na dinâmica de negociação federativa, haja vista a existência de uma cultura política pouco afeita à concertação participativa no sentido de conservar uma prática que vise o equilíbrio estrutural e a consecução de objetivos estratégicos em comum no âmbito da Federação. A essência da cooperação consiste que a realização de determinadas ações públicas não pode ser 
atribuição exclusiva ou hegemônica de um dos entes federados, já que num sistema federativo há interdependência e interesses comuns.

Isso não quer dizer que a forma competitiva do federalismo tenha que ser eliminada, pois é preciso atentar-se para o fato de que o federalismo é necessariamente conflitivo (9). A própria ideia supra-apontada de negociação federativa pressupõe um complexo mix de competição e cooperação que produz uma síntese que acomoda e conforma um pacto. Cooperação também não significa a imposição de formas de participação conjunta, mas a instituição de mecanismos de parceria consensualmente acordados entre seus participantes. A prática cooperativa, segundo Abrucio (9), é primordial para a otimização de recursos comuns, para a criação de um associativismo intergovernamental, como o compartilhamento de informações que ajudem o aperfeiçoamento de políticas públicas e a troca de experiências de boa gestão. Não menos importante, possibilita maior equilíbrio regional, principalmente num país marcado por abissais desigualdades regionais como é o caso brasileiro, preservando inclusive a unidade federativa.

Mas para que esse ambiente, por natureza conflitivo, possa funcionar de maneira harmônica e que a cooperação possa fluir preservando a autonomia e a interdependência dos atores do processo, é necessária que haja uma coordenação federativa enquanto ferramenta institucional de soldagem desse modelo. Geralmente, a coordenação é relacionada ao federalismo fiscal, que, por sua vez, se baseia na capacidade do Governo Central de alocar, distribuir e redistribuir os recursos materiais e financeiros entre as esferas subnacionais, procurando manter o equilíbrio estrutural e um quadro de justiça fiscal (6). Para além do aspecto fiscal, Abrucio lembra que a coordenação federativa "pode realizarse, em primeiro lugar, por meio de regras legais que obriguem os atores a compartilhar decisões e tarefas - definição de competências no terreno das políticas públicas" (9). A existência de espaços de participação dos próprios entes e a existência de cortes constitucionais também conformam aspectos da coordenação federativa, cabendo de fato ao Governo Central papel de destaque, não somente pela questão fiscal e financeira ${ }^{5}$, mas pela possibilidade e dever que a União possui de "de arbitrar conflitos políticos e de jurisdição, além de incentivar a atuação conjunta e articulada entre os níveis de governo no

\footnotetext{
${ }^{5}$ Refere-se ao fato de que os governos subnacionais convivem com dificuldades de ordem financeira e administrativa que dificultam a assunção de encargos e o caso brasileiro talvez seja uma das grandes amostras disso.
} 
terreno das políticas públicas", evitando, ao mesmo tempo, a construção de uma determinada hierarquia centralizadora (9).

A Constituição de 1988 traz, na questão federativa, aquilo que Lassance (3) denomina de "federalismo radical". Os ventos renovadores do período da redemocratização trouxeram novos personagens para a arena política, fator este que propiciou inovações institucionais dentro de uma nova agenda para o país. O início do ocaso do regime ditatorial veio acompanhado pelo recrudescimento dos movimentos sociais e o surgimento de uma nova geração de governadores e prefeitos que, referendados pelo voto popular, formaram uma forte aliança de matriz federalista (3), impulsionando mudanças institucionais importantes que desaguaram nos debates da Constituinte. Nesse contexto, SUS foi forjado enquanto instituição de caráter federativo e balizado pela descentralização político-administrativa. A normatização constitucional estabeleceu o direito à saúde, com ações e serviços que constituem competências materiais comuns da União, Estados, Distrito Federal e Municípios, cabendo aos últimos o papel estratégico de provedor, com a cooperação técnica dos outros entes.

A Lei no 8.080/1990 e a Lei no 8.142/1990, que compõem o que se costumou designar de Lei Orgânica da Saúde, aparecem como alicerces do que se pode entender como "federalismo sanitário brasileiro", na medida em que dispõem acerca do dever de todos os entes federados de atuar para a promoção, proteção e recuperação da saúde, preservando a autonomia de cada esfera de governo para a gestão do sistema nos limites do seu território. Extrai-se daí a categoria que talvez seja uma das manifestações fenomênicas mais expressivas quando se examina o processo político de consolidação do SUS: a regionalização da saúde. Importa dizer que ela também integrava o rol de proposições em debate nos movimentos sociais que propugnavam reformas setoriais que superassem as desigualdades geradas pelo processo de constituição do capitalismo brasileiro e, consequentemente, pelo padrão de intervenção e atuação do Estado em políticas sociais (10). Na perspectiva do movimento político pela reforma, a regionalização era defendida como instrumento essencial para a integralidade da atenção e para a equidade no acesso às ações e aos serviços, na concretização do direito universal à saúde (10). 


\section{Regionalização: determinações conceituais e etapas no processo de constituição do SUS}

Para compreender a regionalização é preciso desvelar suas determinações a partir daquilo que a geografia denomina de território. Qualquer desenho de política pública necessita levar em consideração o território como eixo basilar, concebendo-o como espaço de reprodução do poder. É preciso apreender o território em sua dimensão concreta, como objetos e ações, sinônimo de espaço humano e habitado, fundamento do trabalho, da residência e das trocas materiais e espirituais (11) (12). Assim, o território, como objeto de política pública, se manifesta como conteúdo, meio e processo das relações sociais (10), permeado pela história de diferentes lugares, na qual diversas territorialidades podem ser construídas.

Dentro da dinâmica da cooperação, a regionalização é prática de coordenação política e área de cooperação intersetorial articulada num processo de configuração das ações governamentais. Apresenta-se como ferramenta de mobilização de esforços colaborativos e de aperfeiçoamento democrático, já que se trata de produto de um território perpassado por interesses econômicos, políticos e sociais e cuja permanente tensão resulta em territorialidades.

Mas, tratando-se de um princípio do SUS, em qual fundamentação teórica a regionalização se assenta? Para Duarte, Pessoto, Guimarães et al. (13), a regionalização pode ser compreendida a partir da geografia e da epidemiologia, o que significa dizer que há o processo de regionalização dos serviços, isto é, a organização do sistema de modo a torná-lo mais eficiente e eficaz, cumprindo os objetivos de universalidade, integralidade e equidade da maneira mais racional; e outro, no qual há a criação de regiões de saúde, a partir do perfil epidemiológico de determinada população vivendo em determinado território.

A regionalização enquanto diretriz política estratégica do SUS seguiu em processo de desenvolvimento no decorrer dos anos subsequentes à promulgação da Constituição de 1988. A própria Lei nํ. 8.080/90 reitera os mandamentos previstos no supracitado dispositivo constitucional e define competências, dada a criação de redes regionalizadas e hierarquizadas de saúde, nas quais a direção municipal do SUS deve participar do planejamento, programação e organização, em articulação com sua direção estadual.

A década em que se constituiu organicamente o SUS destacou-se não exatamente pela descentralização associada à regionalização, mas pela ênfase na transferência de 
responsabilidades e competências em direção aos municípios. A forma jurídica pela qual esse processo ocorreu foi a edição das Normas Operacionais Básicas (NOB) do Ministério da Saúde.

A primeira delas, a NOB-SUS 01/91, foi editada ainda sob a égide do INAMPS e, de certa forma, inaugura os percalços que a regionalização do SUS passaria a enfrentar nos anos subsequentes, cuja síntese pode ser caracterizada por "um discurso federativo e uma prática submetedora". É importante frisar que a Lei $n^{\circ}$. 8.080/1990, em seu art. 35, estabeleceu que as transferências de valores para os entes subnacionais obedeceriam aos seguintes critérios: a) população; b) perfil epidemiológico e demográfico; c) capacidade instalada; d) complexidade da rede de prestação de serviços de saúde; e e) contrapartida financeira. Além disso, o art. $3^{\circ}, \S 2^{\circ}$, da Lei $n^{\circ}$. 8.142/1990, estipulava (e anda o mantém) um piso de $70 \%$ do montante das transferências a ser repassado aos municípios. Entretanto, o caminho trilhado pela normativa do INAMPS seguiu a forma de convênios, respeitando o critério populacional do IBGE, o empenho global e índice de reajuste com base na unidade de cobertura ambulatorial (UCA). A consequência de tal política foi um recuo nas transferências financeiras aos municípios, que passaram a ter mais encargos sem os recursos necessários (14), a centralização do sistema de informação e gerenciamento, a negligência das ações e serviços de vigilância sanitária e epidemiológica para fins de critérios de financiamento etc. Todo esse quadro desenhado pela NOB-SUS 01/91 provocou uma reação de gestores e especialistas para que se alterassem as regras em prol daquilo que Carvalho designou de "a ousadia de cumprir e fazer cumprir a lei" (15).

A mobilização em fazer cumprir a lei resultou na edição da NOB-SUS 01/93, que descreveu a regionalização como um dos pressupostos que fundamentam a construção do SUS,

entendida como uma articulação e mobilização municipal que leve em consideração características geográficas, fluxo de demanda, perfil epidemiológico, oferta de serviços e, acima de tudo, a vontade política expressa pelos diversos municípios de se consorciar ou estabelecer qualquer outra relação de caráter cooperativo. (16).

A edição da NOB-SUS 01/93 enquadrou estados e municípios conforme a "condição de gestão", pautando o financiamento às capacidades técnicas e operativas de cada ente. Para Santos e Andrade (14), essa normativa foi de grande importância para o processo de descentralização do SUS por consolidar o entendimento de que os entes subnacionais são 
gestores do sistema e não meros "prestadores de serviços do Ministério da Saúde". O pacote inovador da NOB-SUS 01/93 traz, além deste, a adoção do critério global de repasse de parcela de recursos da União; a transferência de recursos pela modalidade "fundo a fundo" (regulamentado pelo Decreto n‥ 1.232, de 30 de agosto de 1994) e o estabelecimento de estratégias importantes para a ampliação das relações intergovernamentais, como a institucionalização da Comissão Intergestores Bipartite $(\mathrm{CIB})^{6}$, funcionando como espaço de negociação, articulação e pactuação.

Já a NOB-SUS 01/96 deu pouca ênfase à regionalização, mas estabeleceu instrumentos de planejamento que consubstanciaram redes regionalizadas e hierarquizadas de serviços, como a elaboração da Programação Pactuada Integrada (PPI). Por outro lado, caso os municípios não se habilitassem enquanto gestores do sistema em alguma das condições de gestão, a normativa impôs a estes o papel de prestadores de serviço da União, além de ter criado um sem-número de modalidades de repasses financeiros vinculados por programas, projetos e ações que inauguraram, nos dizeres de Santos e Andrade (14), a "era da cenoura e da vara"7, situação na qual as transferências constitucionais obrigatórias eram condicionadas à adesão "voluntária" dos entes subnacionais às iniciativas do Governo Federal, violando a autonomia dessas esferas em formular suas políticas de acordo com realidades locais.

Reiterando a afirmação supracitada, Ribeiro (10) discorre que, nos anos 1990, as estratégias governamentais no âmbito federal priorizaram o fortalecimento da gestão descentralizada do SUS nos estados e municípios, mormente nestes últimos. Nesta época, proliferaram-se iniciativas de associação intermunicipal para o estabelecimento de consórcios de saúde. No entanto, evidenciou-se que o processo de descentralização rumo a uma estrutura municipalizada, em que pese os avanços obtidos em termos de transferências de recursos, de relativa expansão de uma rede municipal de serviços e do fortalecimento da capacidade institucional de estados e municípios na gestão, não foi

\footnotetext{
${ }^{6}$ A Comissão Intergestores Tripartite (CIT) já havia sido instituída pela Portaria GM/MS no 1.180/1991 (24).

${ }^{7}$ Embora tratar-se de uma expressão da linguagem popular, que quer dizer algo como "se não se consegue algo por bem, então consegue-se por mal", aqui ela assume os mesmos contornos empregados por Marçal Justen Filho, um dos grandes mestres do Direito Administrativo brasileiro, em parecer jurídico (25) no qual aborda a aceitação voluntária das políticas federais por parte dos entes subnacionais, tomando emprestado o termo "The Carrot and the Stick", do autor estadunidense Eric Stein, que a cunhou para tratar da técnica política adotada pela esfera federal daquele país de oferecer fundos aos governos estaduais em troca da aceitação. por parte destes, de regras federais.
} 
suficiente para a consecução dos objetivos do SUS, haja vista a heterogeneidade e disparidades regionais existentes no país, com expressiva maioria de municípios de pequeno porte, trazendo dificuldades no sentido do planejamento, da execução e da regulação. Além disso, a fragilidade nos pactos estabelecidos entre estados e municípios quanto à divisão de responsabilidades e de gestão das unidades de saúde dificultou a organização de sistemas de saúde articulados microrregionalmente (14). Identificada a necessidade de racionalização do sistema, buscou-se combinar os seguintes princípios organizativos: descentralização, com maior responsabilidade e autonomia dos municípios em relação à gestão de seus sistemas; regionalização, com foco no planejamento territorial; e hierarquização, por intermédio da estruturação de redes assistenciais funcionais e resolutivas.

À vista disso, foram publicados dois atos normativos para equalizar as questões apontadas no diagnóstico do processo das normativas anteriores e que intentam em responder as diretrizes acima apontadas: as Normas Operacionais da Assistência à Saúde do SUS 01/2001 e 01/2002 (NOAS SUS 01/2001 e NOAS SUS 01/2002). A primeira instituiu estratégias de planejamento para a constituição de redes regionais de saúde com o objetivo de "promover maior equidade na alocação de recursos e no acesso da população às ações e serviços de saúde". Introduziu a concepção dos módulos assistenciais, microrregiões, macrorregiões e regiões, expressas no Plano Diretor de Regionalização (PDR), com exigência de conteúdo mínimo, que procura atender as necessidades identificadas, de acordo com as prioridades de intervenção.

O objetivo geral da NOAS SUS 01/2001 foi "promover maior equidade na alocação de recursos e no acesso da população às ações e serviços de saúde em todos os níveis de atenção". Para tanto, estabeleceu a regionalização como método de organização assistencial, na medida em que dispôs:

A macroestratégia de regionalização deverá contemplar uma lógica de planejamento integrado de maneira a conformar sistemas funcionais de saúde, ou seja, redes articuladas e cooperativas de atenção, referidas a territórios delimitados e a populações definidas, dotadas de mecanismos de comunicação e fluxos de inter-relacionamento que garantam o acesso dos usuários às ações e serviços de níveis de complexidade necessários para a resolução de seus problemas de saúde, otimizando os recursos disponíveis.

A necessidade de revisão de alguns aspectos da NOAS SUS 01/2001 levou o Ministério da Saúde (MS) a editar a NOAS SUS 01/2002, que teve por finalidade ampliar a 
responsabilidade dos municípios nos cuidados com a atenção básica e a criação de mecanismos de fortalecimento da estratégia de hierarquização do sistema e da capacidade de gestão, pontos que, em termos gerais, não alteraram as diretrizes preconizadas pela norma revogada.

O desenvolvimento da agenda da regionalização da saúde no contexto federativo passou a ser norteado pela necessidade de qualificação, aperfeiçoamento e melhor definição de responsabilidades sanitárias e de gestão entre entes federados nas regiões de saúde, em torno de prioridades de impacto na situação de saúde local. Nessa esteira, veio o Pacto pela Saúde (Portaria n‥ 399/2006) ${ }^{8}$, que formalizou oficialmente compromissos entre os gestores federal, estaduais e municipais de equacionar dificuldades acumuladas pelo que se avaliou, à época, como "excessiva indução nacional dos processos locais por meio de normas gerais pouco sensíveis a um país de dimensões continentais e com grandes desigualdades, e, pelo complexo e detalhado conteúdo técnico-processual que caracterizava a regulação anterior" (10).

O Pacto pela Saúde significou um novo patamar na forma de financiamento, definição de responsabilidades, estipulação de metas e compromissos sanitários entre os gestores, sistematizado nos seguintes pontos: (i) de gestão do SUS; (ii) regionalização; (iii) planejamento e programação; (iv) regulação, controle, avaliação e auditoria do sistema; (v) gestão do trabalho; (vi) educação em saúde; e, (vii) ampliação da participação e do controle social (17). Com isso, os gestores assumiram o compromisso público de enfatizar as prioridades enxertadas nos três componentes do programa: Pacto pela Vida, Pacto em Defesa do SUS e Pacto de Gestão do SUS. Este último, determina responsabilidades dos entes federativos dentro das competências concorrentes sobre o que cada um deve realizar, levando em consideração as disparidades locais e regionais do território nacional, implicando numa lógica de descentralização e regionalização do SUS de maneira desburocratizada, por intermédio das regiões sanitárias e dos Colegiados de Gestão Regional (CGR), cuja criação talvez tenha sido a maior inovação do Pacto. O objetivo dessa instância interlocutória é justamente o estabelecimento de relações horizontais entre os governos municipais através do emprego de processos decisórios compartilhados. $\mathrm{Na}$ direção do federalismo

8 Compõem o Pacto pela Saúde outros instrumentos normativos, quais sejam: Portaria nº 699/2006; Portaria ํo. 3.085/2006; Portaria №. 3.382/2006; e Portaria ํo. 204/2007. 
cooperativo, o CGR apresenta aquilo que, conforme já visto, conforma um dos eixos da cooperação e coordenação: a negociação direta entre os governos locais e a indução de um ente central. Logo, os municípios que compõem determinada região de saúde se interagem em cogestão horizontal, ao passo em que a esfera estadual tem a tarefa de coordenar as diversas relações estabelecidas (23).

Outro fator importante é o financiamento. A Portaria GM n‥ 204/2007 estabeleceu seis blocos de financiamentos pelos quais os recursos federais seriam transferidos, na modalidade fundo a fundo, aos entes subnacionais: I - Atenção Básica; II - Atenção de Média e Alta Complexidade Ambulatorial e Hospitalar; III - Vigilância em Saúde; IV - Assistência Farmacêutica; V - Gestão do SUS; e VI - Investimentos na Rede de Serviços de Saúde, sendo que cada bloco é constituído por componentes, de acordo com as ações e serviços de saúde pactuados e a eles correspondentes. Muito embora a edição dessa Portaria viesse como solução à fragmentação dos repasses, não rompeu com a lógica da "cenoura e da vara", na medida em que a transferência continuou vinculada ao atendimento de condicionalidades ${ }^{9}(14)$.

Percebe-se até aqui que a estratégia para a regionalização do SUS sustentou-se em grande medida pela adoção de programas e projetos federais pelos entes subnacionais como contrapartida para financiamento. Identificada esta questão, mais uma vez tentou-se inovar com a edição do Decreto nº. 7.508, de 28 de junho de 2011. Em termos de regionalização da saúde, a grande inovação do Decreto é o Contrato Organizativo de Ação Pública da Saúde (COAP), enquanto instrumento de articulação interfederativa para o estabelecimento de execução de ações e serviços no âmbito de uma região de saúde ${ }^{10}$. Trata-se de um acordo de cooperação pactuado entre entes da federação cuja função primordial consiste em estruturar a integração das ações e serviços de saúde em uma rede regionalizada e hierarquizada, mediando as responsabilidades sanitárias de cada ente envolvido, bem como definindo as ferramentas de gestão, como os indicadores e metas de

\footnotetext{
${ }^{9}$ Anunciado em reunião da CIT em janeiro de 2017, o chamado "Projeto SUS Legal" estipula o fim dos seis blocos de financiamento e a criação de dois tipos de modalidades de repasse classificada nas categorias econômicas: de custeio e de capital, contudo sem, até esta data, qualquer alteração normativa.

10 O Decreto $n^{\circ}$. 7.508/2011 define, em seu art. $2^{\circ}$, I, a região de saúde como "espaço geográfico contínuo constituído por agrupamentos de Municípios limítrofes, delimitado a partir de identidades culturais, econômicas e sociais e de redes de comunicação e infraestrutura de transportes compartilhados, com a finalidade de integrar a organização, o planejamento e a execução de ações e serviços de saúde" (32).
} 
saúde, critérios de avaliação de desempenho, recursos financeiros a serem disponibilizados, mecanismo de controle e fiscalização de sua execução (18).

É preciso compreender o COAP a partir de uma perspectiva de um arranjo interfederativo assentado no princípio da cooperação e do paradigma da governança regional. Santos e Andrade (14) afirmam que os consensos obtidos nos fóruns de articulação interfederativa são insuficientes para dar sequência às ações resultantes dos pactos, especialmente num contexto político-federativo atravessado por baixa institucionalidade e participação, fragmentação político-partidária e de atores federativos e disparidades regionais abissais. Assim, justifica-se a consubstanciação de instrumentos jurídicos para dispor acerca da organização e a integração das ações e serviços de saúde, com definição das responsabilidades sanitárias (executiva, organizativa, financeira e de controle) de cada ente dentro de uma região de saúde.

Por se tratar de um contrato celebrado por entes públicos, pode-se dizer que o COAP é uma "espécie" que pertence ao "gênero" contrato administrativo. No entanto, é preciso ressaltar que se trata de uma "espécie" diferente, na medida em que não envolve uma relação bilateral. Justen Filho (19) diria se tratar de "contrato administrativo plurilateral ou organizacional”, no qual um conjunto de entes se obrigam reciprocamente a desencadearem ações para a obtenção de certo resultado de interesse comum. Santos e Andrade (14), classificam estes tipos de instrumentos como novas formas de "negociação pública", tomando de empréstimo categorias como "Administração Pública Consensual", "contratualização de políticas públicas" etc., já que regulam atividades nas quais se destacam procedimentos negociais que deságuam em conciliações e compatibilização dos interesses em torno de um objetivo comum.

Em que pese aparentar um atraente instrumento de pactuação federativa, que corresponsabiliza cada ente por intermédio de um contrato que especifica atribuições sanitárias que cada um deva ter, por que, passado tanto tempo da edição da criação do COAP, apenas os estados do Ceará e do Mato Grosso do Sul o celebraram, muito embora outros tenham feito discussões e implementações parciais do Decreto, como a configuração das regiões de saúde?

Talvez tal pergunta não tenha uma resposta imediata e objetiva e nem é propósito deste trabalho fazê-la, mas um caminho para encontrar alguns motivos da pouca adesão ao 
COAP pelo conjunto dos atores da federação quiçá esteja em uma das próprias razões que motivaram a criação deste instrumento.

O processo de regionalização do SUS, apesar do aperfeiçoamento ao longo dos anos, nunca foi marcado pelo total empenho dos gestores dos três níveis. Ao regular as responsabilidades dos entes perante a população e os recursos financeiros que cada um dos contratantes disponibilizarão para a execução dos serviços de saúde na região de saúde, o COAP parece como um corpo estranho num sistema notabilizado pelas dificuldades operativas, "incluindo as dimensões continentais do país, as desigualdades e diversidades regionais, a abrangência das atribuições do Estado na saúde e a multiplicidade de atores envolvidos na condução e prestação da atenção à saúde" (20). Ademais, uma Federação atravessada pela falta de criatividade em estabelecer novos paradigmas para um rearranjo administrativo, pela competição de seus entes na repartição do fundo público na forma de impostos (e orçamento) e pela intensa falta de concertação política dada a fragmentação partidária, não constituem exatamente um ambiente propício para ousadas iniciativas em termos de política pública. Enfim, tem-se um quadro atual em que foram estabelecidas, desde a aprovação do Decreto 7.508/2011, 438 regiões de saúde no país, muitas das quais incapazes de atender 95\% das necessidades de saúde de sua população (21).

\section{Considerações Finais}

A regionalização da saúde é uma estratégia que integra as políticas de redemocratização desde a CF/88, sendo que neste tempo se notabilizou com a construção de novos arranjos institucionais que prezam pela descentralização federativa e a autonomia dos entes federados, obedecendo ao movimento iniciado pela própria CF/88 de construção de um federalismo cooperativo.

A essência deste federalismo de tipo cooperativo consiste na ideia de que a realização de determinadas ações públicas são fruto da interação política dos entes envolvidos e não da atribuição exclusiva de um deles, em razão da interpendência e interesses comuns. No entanto, é preciso entender que o federalismo é eminentemente conflitivo e que cooperação não exclui o caráter competitivo, devendo este sistema se equilibrar num mix destas características, produzindo síntese que acomoda e conforma um pacto.

Obviamente, o processo de regionalização do SUS não se esgota em determinado instrumento. Como parte de um movimento complexo que envolve escolhas políticas, 
conjunturas econômico-sociais, desenvolvimento de questões epidemiológico-sanitárias etc., está sempre em adaptação e aperfeiçoamento.

É certo que a tensão entre centralização e descentralização permeia dificuldades de implementação da regionalização, mas é importante suscitar outros fatores: existe resistência por parte de setores de profissionais da saúde, de gestores, do chamado complexo médico-industrial e do mercado complementar e suplementar da saúde na consolidação de um SUS estruturado e que atenda com qualidade a cidadania brasileira. Certos interesses políticos e econômicos destes setores podem conflitar com o pleno funcionamento de regiões de saúde que articulem as redes de forma ordenada e voltada para prestar um bom atendimento à população e que, justamente por isso, exige maior participação do fundo público para o financiamento do direito à saúde.

A análise da regionalização no SUS não ultrapassa o dilema que reside entre o financiamento e a gestão. Contudo, da narrativa exposta, a ênfase está no ordenamento fiscal do federalismo nacional e consequente subfinanciamento (crônico) da área da saúde, que por sua vez tem notório impacto na conformação de regiões e rede de atenção à saúde, que por deverem constituir conjunto de ofertas de ações e serviços de saúde adequados à necessidade da população, em determinado território, carecem, por óbvio, de custeio e investimento apropriados.

\section{Referências}

1. Sampieri RH, Callado CF, Lúcio MPB. Metodologia de pesquisa. Tradução: Daisy Vaz de Moraes. Porto Alegre: Penso, 2013.

2. Creswell JW. Projeto de pesquisa: métodos qualitativo, quantitativo e misto. Tradução Luciana de Oliveira da Rocha. Porto Alegre: Artmed, 2007.

3. Lassance A. Federalismo no Brasil: trajetória institucional e alternativas para um novo patamar de construção do Estado. In: Linhares PTFL, Mendes CC, Lassance A, organizadores. Federalismo à brasileira: questões para discussão. Brasília: Ipea, 2012.

4. Salvador E. Fundo Público e Financiamento das Políticas Sociais no Contexto do Federalismo Brasileiro do Séc. XXI. Revista Política Social e Desenvolvimento. 2014, 5(1):14-38.

5. Fiori JL. O federalismo diante do desafio da globalização. In: Affonso RBA, Silva PLBS, organizadores. A federação em perspectiva: ensaios selecionados. Sao Paulo: Fundap, 1995. 
6. Affonso RBA. Crise da Federação no Brasil. Ensaios, FEE Porto Alegre, 1994, 15(2):321-337. Disponível em

https://revistas.fee.tche.br/index.php/ensaios/article/view/1704/2071. Acesso em 2.9.2017.

7. Amaral Filho J. Federalismo brasileiro e sua nova tendência de recentralização.

Fortaleza, 2004. Disponível em:

http://conteudo.ceara.gov.br/content/aplicacao/sdlr/desenv urbano/gerados/f1texto.pdf

Acesso em 20.9.2017.

8. Arretche M. Federalismo e políticas sociais no Brasil: problemas de coordenação e autonomia. São Paulo em Perspectiva. 2004, 18(2):17-26. Disponível em: https://dx.doi.org/10.1590/S0102-88392004000200003. Acesso em 6.9.2017.

9. Abrucio FL. A coordenação federativa no Brasil: a experiência do período FHC e os desafios do governo Lula. Revista de Sociologia e Política, 2005, 24(1):41-67. Disponível em https://dx.doi.org/10.1590/S0104-44782005000100005. Acesso em 24.10.2017.

10. Ribeiro PT. Perspectiva territorial, regionalização e redes: uma abordagem à política de saúde da República Federativa do Brasil. Saúde e Sociedade, 2015, 24(2):403-412. Disponível em http://plataformapoliticasocial.com.br/wp-content/uploads/2015/06/DossieRegionaliza\%C3\%A7\%C3\%A3o.pdf Acesso em 23.9.2017.

11. Santos M. O retorno do território. In: Santos M, Silveira MA, organizadores. Território: globalização e fragmentação. São Paulo: Hucitec; 1996.

12. Santos M. O dinheiro e o território. In: Santos M, Bertha BK, organizadores. Território, territórios: ensaios sobre ordenamento territorial. São Paulo: Lamparina, 2007.

13. Duarte LS, Pessoto UC, Guimarães RB, Heimann LS, Carvalheiro JR, Cortizo CT et al. Regionalização da saúde no Brasil: uma perspectiva de análise. Saude soc. 2015, 24(2):472-485. Disponível em:

http://www.scielo.br/scielo.php?script=sci arttext\&pid=S0104-

$12902015000200472 \&$ lng=en. Acesso em 10.10.2017.

14. Santos L, Andrade LOM. SUS: O espaço da gestão inovada e dos consensos interfederativos. Campinas: Saberes Editora, 2007.

15. Carvalho GCM. O momento atual do SUS... a ousadia de cumprir e fazer cumprir a lei. Saude e Sociedade, 1993, (1)2:9-24. Disponível em http://www.scielo.br/pdf/sausoc/v2n1/03.pdf. Acesso em 2.2.2018.

16. Ministério da Saúde. Portaria nํ545, de 20 de maio de 1993. Estabelece normas e procedimentos reguladores do processo de descentralização da gestão das ações e serviços de saúde, através da Norma Operacional Básica SUS 01/93. Disponível em: http://bvsms.saude.gov.br/bvs/saudelegis/gm/1993/prt0545 2005 1993.html Acesso em 2.2.2018

17. Ministério da Saúde. Portaria no 399, de 22 de fevereiro de 2006. Divulga o Pacto pela Saúde 2006 - Consolidação do SUS e aprova as Diretrizes Operacionais do Referido 
Pacto. Disponível em:

http://bvsms.saude.gov.br/bvs/saudelegis/gm/2006/prt0399 2202 2006.html Acesso em 3.2.2018

18. Brasil. Decreto no 7.508, de 28 de junho de 2011. Regulamenta a Lei no 8.080 , de 19 de setembro de 1990, para dispor sobre a organização do Sistema Único de Saúde-SUS, o planejamento da saúde, a assistência à saúde e a articulação interfederativa, e dá outras providências. Disponível em http://www.planalto.gov.br/ccivil 03/ ato20112014/2011/decreto/d7508.htm Acesso em 3.9.2017.

19. Justen Filho M. Parecer sobre minuta de anteprojeto de Lei da Política Nacional de Saneamento Básico. Brasília. 2005.] Disponível em: http://www.planalto.gov.br/ccivil 03/revista/Rev 72/pareceres/saneamento complementar MarcalJustenFilho 1.pdf Acesso em 12.10.2017.

20. Silva HP, Mota PHS. Regionalização da saúde e integração dos serviços: evidências sobre o atual estágio de conformação das regiões e redes de atenção à saúde na perspectiva dos municípios brasileiros. Novos Caminhos, 2015.

21. Santos L, Campos GW. SUS Brasil: a região de saúde como caminho. Saúde Soc. 2015, 24(2):438-446. 